\title{
Mortality following hip fractures managed with hemiarthroplasty in the elderly in South Africa
}

\author{
du Toit $A L^{1}{ }^{1}$, van der Merwe JF² \\ ${ }^{1} \mathrm{MBChB}(\mathrm{UFS}), \mathrm{FC}$ Orth (SA), MMed(Orth)(UFS); Registrar, Department of Orthopaedic Surgery, University of the Free State \\ ${ }^{2} \mathrm{MBChB}(\mathrm{US}), \mathrm{MMed}($ Orth)(UFS); Head of Arthroplasty Unit, Department of Orthopaedic Surgery, University of the Free State
}

Corresponding author: Dr ALJ du Toit, email: draljdutoit@gmail.com; tel: 0118804901

\begin{abstract}
Background: Limited studies are available documenting the demographics and mortality of hip fractures following surgery in South Africa and in Africa. The aim of this study was to evaluate short- and long-term mortality following displaced intracapsular femur neck fractures managed in the elderly with cemented hemiarthroplasty surgery at our institution.

Methods: Data was collected from 561 patients who were treated from 1 May 2001 to 30 April 2014. Mortality was confirmed with the National Population Register.

Results: The mean age was 77.96 years $(\mathrm{SD}=9.76)$ with more female $(69.2 \%)$ compared to male $(30.8 \%)$ patients. Male patients presented at a younger age (mean=74.6) than female patients (mean=79.4; $p<0.0001$ ). The incidence of the affected side was similar, with right-sided hip fractures (49\%) almost equalling left-sided hip fractures (51\%). The overall cumulative all-cause mortality rates for patients were: $12.5 \% 30$ days post-surgery, $22.7 \% 90$ days post-surgery, $27.9 \%$ six months post-surgery and $34.3 \%$ one year post-surgery, respectively.

Conclusion: The results from this study showed a high mortality rate in comparison to international studies. Future research is required to identify risk factors associated with early mortality following hip fractures and this might help improving outcomes in our elderly patient population.
\end{abstract}

Level of evidence: Level 4

Key words: hip, fractures, elderly, mortality, hemiarthroplasty

Citation: du Toit ALJ, van der Merwe JF. Mortality following hip fractures managed with hemiarthroplasty in the elderly in South Africa. SA Orthop J 2018;17(3):30-34. http://dx.doi.org/10.17159/2309-8309/2018/v17n3a3

Editor: Prof Anton Schepers, University of the Witwatersrand

Received: December 2016

Accepted: June 2018

Published: August 2018

Copyright: @ 2018 du Toit ALJ. This is an open-access article distributed under the terms of the Creative Commons Attribution Licence, which permits unrestricted use, distribution and reproduction in any medium, provided the original author and source are credited.

Funding: No funding was received for this study.

Conflict of interest: The authors declare they have no direct or indirect conflict of interests related to this review article. 


\section{Introduction}

Hip fractures in older patients remain a common cause for emergency and orthopaedic department admissions and often lead to functional limitations, reduced quality of life, postoperative complications and an increased mortality. ${ }^{1}$ Improved healthcare services and recent advances in medicine will likely result in a higher incidence of hip fractures in future as life spans increase.

Numerous journal publications have documented patient outcomes after surgical treatment of hip fractures with specific reference to mortality and demographics. Mortality rates one year post-fracture, regardless of fixation method, typically vary between $11 \%$ and $38 \%$; with geographical variations being reported. . $^{2-10}$

Surgical intervention is currently accepted as the standard treatment of choice in the management of displaced intracapsular femoral neck fractures and has been shown to decrease mortality and improve morbidity when compared to non-operative management. ${ }^{5}$ Studies documenting patients treated with hemiarthroplasty for displaced intracapsular femur neck fractures have demonstrated similar, and sometimes higher, one-year mortality rates of between $25 \%$ and $38 \%$ when compared to management with total hip arthroplasty. These rates are, however, still lower than the mortality rates of patients who were managed non-operatively. $3,5,11$

Few studies are available describing the overall extent of hip fractures in Africa, and South Africa in particular, and no studies could be found documenting demographics and mortality following surgical management with hemiarthroplasty in South Africa. This study evaluated the local mortality rate of hip fractures treated with hemiarthroplasty surgery and compared it to international data available from other regions and institutions.

\section{Methods}

This descriptive study analysed retrospective data of the outcomes of a historical cohort of patients. Data was obtained from the theatre register and patient files from the Department of Orthopaedic Surgery at Universitas Academic Hospital Annex, Bloemfontein, Free State. Data of all patients surgically managed by means of a hemiarthroplasty for a displaced intracapsular neck of femur fracture was collected for a 13-year period from 1 May 2001 to 30 April 2014.

Inclusion criteria for this study were all patients with a displaced intracapsular femur neck fracture that were managed with a cemented hemiarthroplasty prosthesis. Exclusion criteria were all patients who presented with a displaced femoral neck fracture who were managed with either a total hip arthroplasty or reduction and internal fixation. Patients with incomplete demographic data and who could not be confirmed as either alive or demised were also excluded.

The decision on the type of surgical management of the patient was made by the consultant specialist in charge, taking into consideration the patient's pre-injury mobility, comorbidities and age. Patients with advanced age, decreased pre-injury mobility and/or multiple comorbidities were managed by means of a cemented hemiarthroplasty prosthesis.

Data was obtained from the theatre register and the patient's clinical records, namely: age, sex, date of birth, national identification number, date of admission, surgery and date of death (if applicable), affected side operated and type of prosthesis used. The primary endpoint of this study was to evaluate overall all-cause mortality at 30 days, 90 days, six months and one year post-surgery. This data was obtained from the patient's file, theatre register and the National Death Register. The National Death Register maintained by the Department of Home Affairs was consulted to confirm the vital status (and date of death, if applicable) of all patients. This information was acquired by supplying the National Death Register with the patient's identification number, which was usually noted in the majority of patients' records. All data was collected and recorded electronically in an Excel spreadsheet format by the principal investigator.

Different mortality rates between sexes were analysed by means of chi-square analysis. Descriptive data is presented using frequencies and percentages, as well as means and medians for continuous data. Differences in age of presentation by sex was tested by means of a Student's t-test, and differences in mortality by age were tested using an ANOVA. Finally, age on admission and sex were considered as predictors for mortality using a survival analysis.

Approval to conduct this research was obtained from the Ethics Committee of the Faculty of Health Sciences, University of the Free State (ECUFS 61/2015), Universitas Academic Hospital Annex and the Provincial Department of Health.

\section{Results}

Some 561 patients were managed with hemiarthroplasty surgery over a 13-year period from 1 May 2001 to 30 April 2014 with a minimum follow-up of 12 months post-surgery. Eight patients underwent surgery twice for bilateral non-simultaneous hip fractures sustained in this period, and were thus, initially counted twice in the total of 561.

Table / shows the basic demographic information of the patients. The mean age of all patients requiring surgery was 77.96 years $(S D=9.76)$ with more female $(n=388,69.16 \%)$ patients than male $(n=173,30.84 \%)$. There was, however, a significant difference in the mean age of first or only presentation between males and females $(p<0.0001)$, with male patients presenting at a younger age $($ mean $=74.56, S D=11.1)$ than female patients $($ mean $=79.39$, $\mathrm{SD}=8.72)$.

There was no significant difference in the incidence of the affected side with right-sided hip fractures ( $n=275,49.02 \%$ ) almost equalling left-sided hip fractures ( $n=286,50.98 \%)$. The mean days from admission to surgery was 3.55 days $(S D=3.07)$ with the mean length of hospital stay being 11.90 days (SD=8.59).

Table I: Demographics of patients

\begin{tabular}{l|l}
\hline Characteristics (n=561) & \\
\hline $\begin{array}{l}\text { Age, years (mean, SD) } \\
\text { Female } \\
\text { Male }\end{array}$ & $\begin{array}{l}77.96(9.76) \\
79.39(8.72) \\
74.56(11.09)\end{array}$ \\
$\begin{array}{l}\text { Sex } \\
\quad \text { Female } \\
\text { Male }\end{array}$ & $388(69.16 \%)$ \\
$\begin{array}{l}\text { Affected side } \\
\quad \text { Left } \\
\text { Right }\end{array}$ & $173(30.84 \%)$ \\
$\begin{array}{l}\text { Days of hospital stay (mean, SD) } \\
\text { Days from admission to surgery (mean, SD) }\end{array}$ & $286(50.98 \%)$ \\
\end{tabular}

Table II: Mortality following surgery

\begin{tabular}{|l|l|l|}
\multicolumn{1}{|c|}{ Mortality } & \multicolumn{1}{c|}{ Number } & Cumulative number \\
\hline$<30$ days & $43(12.50 \%)$ & $43(12.50 \%)$ \\
31-90 days & $35(10.17 \%)$ & $78(22.67 \%)$ \\
$91-180$ days & $18(5.23 \%)$ & $96(27.90 \%)$ \\
$181-365$ days & $22(6.40 \%)$ & $118(34.30 \%)$ \\
$>365$ days & $152(44.19 \%)$ & $270(78.49 \%)$
\end{tabular}


Table III: Mortality according to sex and time of demise

\begin{tabular}{|c|c|c|c|c|c|c|}
\hline & $<30$ days & 31-90 days & 91-180 days & $181-365$ days & >365 days & Total \\
\hline Female & 32 (16.49\%) & 27 (13.92\%) & $10(5.15 \%)$ & $15(7.73 \%)$ & $110(56.70 \%)$ & 194 \\
\hline Male & $11(14.47 \%)$ & $8(10.53 \%)$ & $8(10.53 \%)$ & $7(9.21 \%)$ & 42 (55.26\%) & 76 \\
\hline Total & 43 & 35 & 18 & 22 & 152 & 270 \\
\hline
\end{tabular}

Table IV: Median days with 95\% Cl from surgery to demise

\begin{tabular}{|l|c|c|c|}
\hline & $<80$ years & $>80$ years \\
\hline Female & $1292(1019-1783)$ & $711(374-1132)$ \\
\hline Male & $770(473-1468)$ & $649(67-936)$ \\
\hline Total & $1158(863-1468)$ & $673(425-937)$ & $937(464-1043)$ \\
\hline
\end{tabular}

Table V: Comparisons between strata

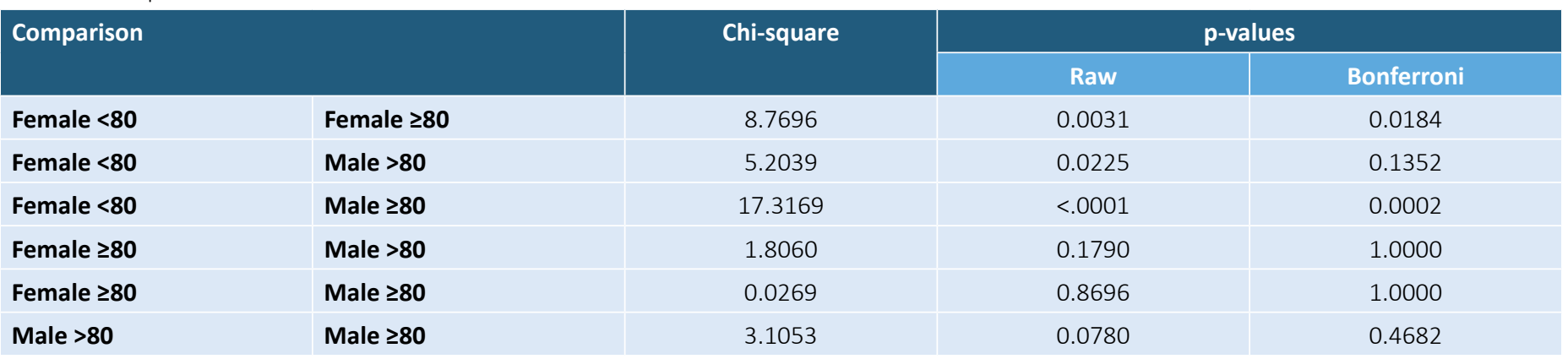

A total of 209 patients (37.79\%) were excluded due to insufficient data, with 344 patients $(62.21 \%)$ of the total study population of 553 patients who could be confirmed as either being alive or dead. Of these patients 74 were confirmed still alive and 270 as being deceased at the end of the period being examined (i.e. April 2015).

The all-cause mortality rates (Table II) for all patients were $43 / 344$ (12.5\%) 30 days post-surgery, 78/344 (22.67\%) 90 days postsurgery, 96/344 (27.90\%) six months post-surgery, and 118/344 (34.30\%) one year post-surgery, respectively. The remainder of the patient group confirmed as deceased, demised more than one year after surgery $(n=152,44.19 \%)$. The median time from surgery to demise was 2.57 years for the whole group.

There were statistically significant differences between some of the mortality groups with respect to age at presentation. The mean age at presentation for the 74 confirmed alive patients (74.43 years), was significantly lower than the mean age at presentation for the 270 confirmed dead patients (78.77 years, $\mathrm{p}=0.0006$ ). The patient group who demised $<30$ days post-surgery had a higher age at presentation than the group who demised 91-180 days post-surgery (difference in mean age $=9.67,95 \%$ $\mathrm{Cl}: 1.48-17.87, \mathrm{p}<0.05)$, and were also older than the group who demised $>365$ days post-surgery (difference in mean age $=5.41$, 95\% Cl: 0.38-10.46, p<0.05).

A Student's t-test on the mean number of days to death after surgery by sex for the 270 confirmed dead patients was not statistically significant, although the females showed a mean number of days to demise of 917.8, while the mean for males was only 699.7 days. This was despite the females presenting for surgery at a generally higher age than men. The mortality ranges by sex are shown in Table III. Student's t-tests conducted separately for males and females on the age of admission by confirmed survival showed that the females confirmed alive ( $n=52$, mean age of presentation $=77.38$ years) were not significantly younger than the females confirmed dead ( $n=194$, mean age of presentation $=79.66$ years, $p=0.0894)$. However, for the males the difference was significant with the 76 confirmed dead males showing a mean age at presentation of 76.50 years, compared to the mean age of presentation of 67.46 for the 22 confirmed alive males ( $p=0.001$ ).

Twenty-four (8.89\%) patients died in hospital, with a median of two days between surgery and death (four died on the day of surgery, a further 19 within 15 days post-surgery, and one at 48 days post-surgery). Sixteen of the patients were female and eight male, respectively. The mean age on admission for the patients who died in hospital was higher (81.79 years) compared to the total admissions group (77.96 years).

The survival analysis used age at admission as a covariate, and also plotted different survival curves for sex. Due to the mean age of the group and studies showing differences in mortality for different age groups, it was decided to further stratify the sample in terms of age, so that patients 80 years and older would be plotted separately. ${ }^{1,12}$ The survival curves of the four strata so defined were found not to be similar $\left(\chi^{2}=19.08, d f=3, p=0.0003\right)$. Table IV shows the median survival times (in days) between the various groups, and Table $V$ shows the log rank tests for comparisons between the strata.

From this, it is evident that females younger than 80 years showed significantly better survival rates than both males and females 80 years and above. Males below 80 years did not show significantly worse survival rates than females below 80, but neither did they show better survival rates than their counterparts 80 years and above, nor females 80 years and above. This inbetween status is very evident in Figure 1, where the plot for the males below 80 years crosses both those of females below 80 and females 80 years and above. The only consistently worse plot is that of males 80 years and above.

\section{Discussion}

This study presents data from a large group of patients at our institution who sustained a displaced intracapsular femoral neck fracture over a 13-year period and is, to our knowledge, the first 


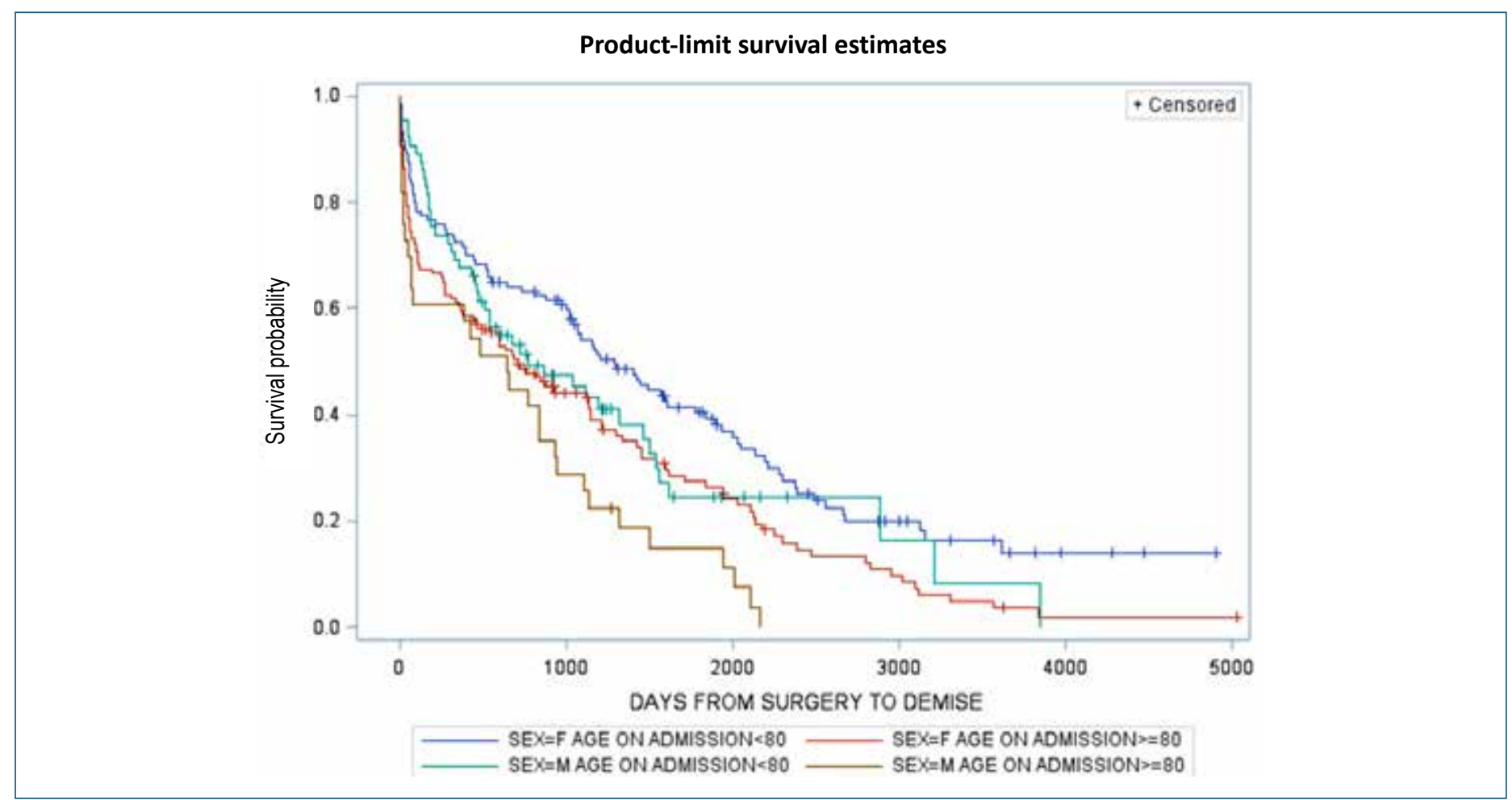

Figure 1. Survival analysis for all patients confirmed dead or alive $(n=344)$

Table VI: Studies from different geographical regions

\begin{tabular}{|c|c|c|c|}
\hline Study/Review & Population & Duration & One-year mortality rate \\
\hline Current study & South Africa & 14 years & $34.30 \%$ \\
\hline Mundi et al. ${ }^{2}$ & North America & 31 years & $20 \%$ \\
\hline \multirow[t]{6}{*}{ Haleem et al. ${ }^{4}$} & International review & 40 years & $22 \%-29 \%$ \\
\hline & North America & & $18 \%$ \\
\hline & Asia & & $10 \%$ \\
\hline & Scandinavia & & $24 \%$ \\
\hline & Europe & & $22 \%$ \\
\hline & United Kingdom & & $28 \%$ \\
\hline Gregory et al. ${ }^{5}$ & United Kingdom & 1 year & $25 \%$ \\
\hline Koh et al. ${ }^{7}$ & Singapore & 5 years & $37.2 \%$ \\
\hline Yoon et al. ${ }^{9}$ & Korea & 4 years & $18.8 \%$ \\
\hline Costain et al. ${ }^{11}$ & Australia & 10 years & $25.2 \%$ \\
\hline Ruiz-Ibán et al. ${ }^{12}$ & Europe & 12 years & $21 \%$ \\
\hline Khan et al. ${ }^{13}$ & United Kingdom & 7 years & $31.4 \%$ \\
\hline Johnston et a $\left.\right|^{14}$ & United Kingdom & 17 years & $30.7 \%$ \\
\hline Yli-Kyyny et al. ${ }^{15}$ & Scandinavia & 10 years & $25.4 \%$ \\
\hline Panula et al. ${ }^{16}$ & Scandinavia & 2 years & $27.3 \%$ \\
\hline
\end{tabular}

study from South Africa evaluating mortality in patients managed operatively by means of a cemented Thompson's hemiarthroplasty. The primary endpoint was evaluating all-cause mortality one year after surgery.

The mean age at presentation was 77.96 years, with the majority of patients being female. In a systematic review of randomised controlled trials over a 31-year period Mundi et al. found similar results with an average age at presentation between 77 and 81 years. However, they found an increase in the average age at presentation over this period. ${ }^{2}$ This trend was also reported by Haleem et al., who found an increase in the mean age at presentation (73-79 years) when reviewing literature over a 40-year period. ${ }^{4}$ They reported the majority of patients presenting with a femoral neck fracture were female (>71 \%), which is comparable to our findings. Our study, however, showed no increase in the mean age at presentation, although our data only spanned 13 years. Both these reviews included only global data over these periods from North America, Europe and Asia, with no studies from Africa. Various other individual studies have confirmed these demographic trends with geographical variations being reported. ${ }^{1,3,6-9}$

The overall all-cause mortality rates for patients in our study 
were $12.5 \% 30$ days post-surgery, $22.67 \% 90$ days post-surgery, $27.90 \%$ six months post-surgery and $34.30 \%$ one year postsurgery, respectively. Studies from different geographical regions (Table VI) have shown much lower mortality rates. Haleem et al. in a review of studies over 40 years found that mortality after a hip fracture ranges from $11-23 \%$ at six months and $22-29 \%$ at one year respectively. ${ }^{4}$ Their review did not, however, include any studies from Africa. Mundi et al. in a systematic review of studies from North America over a 31-year period found a mean oneyear mortality rate of $20 \%$ over this period in surgically managed patients. ${ }^{2}$ Studies from Asia and Scandinavia have shown similar low mortality rates (10\% and $20 \%$ ) with data from Europe (22\%) and the United Kingdom (28\%) showing slightly higher mortality rates. ${ }^{4}$ Yoon et al., however, observed a higher mortality rate than previously reported in the Asian population in Korea, with mortality rates of $18.8 \%$ one year after fracture. ${ }^{9}$

A European study by Ruiz-lbán et al. showed a median survival rate of 4.5 years, compared to our median survival rate of 2.57 years, with a mortality rate of $21 \%$ one year after injury and surgery. ${ }^{12}$ Khan et al., however, reported a higher mortality rate in their series from the United Kingdom with a one-year mortality rate of $31.4 \%{ }^{13}$ This result is comparable to other studies from the United Kingdom with Johnston et al. reporting a similar one-year mortality rate of $30.7 \% .{ }^{14}$ Scandinavian studies showed improved results compared to our data and studies from the United Kingdom with Yli-Kyyny et al. and Panula et al. reporting one-year mortality rates of $25.4 \%$ and $27.3 \%$ respectively. ${ }^{15,16}$

Possible explanations for our higher mortality rates compared include demographic variations in our patient population (e.g. lower life expectancy), higher rate of comorbidities, late presentation to a healthcare institution, limitations in resources or a delay in management. There is also little data available to calculate cause-specific mortality which could explain the increased reported rates of all-cause mortality.

The size of the study population is comparable to similar studies from Asia, Europe and North America. 2,4 This study also provides information on a group of patients in a location not previously studied, thus providing potential future research opportunities in exploring further demographic trends and geographical variations between population groups.

We acknowledge potential limitations in our study. There was a large group of patients ( $n=209,37.79 \%$ ) who could not be included in the final analysis of mortality due to insufficient data recorded at the time of presentation, especially national identification numbers. Only all-cause mortality was calculated as information regarding patient comorbidities, and risk factors could not be consistently collected from available patient records. Future prospective studies documenting and improving on the above could potentially identify individual risk factors that are a cause for an increased patient mortality compared to other regions, or identify differences in treatment methods that contribute to higher mortality rates. Identifying these risk factors and implementing preventative or corrective measures in our individual patient population could potentially improve morbidity and mortality. The above limitations also highlight the importance of maintaining a national multicentre database that would ensure consistent and reliable data collection for future research opportunities.

\section{Conclusion}

The results from this study showed a high mortality rate in comparison to previous international studies. Future research is required to identify risk factors associated with early mortality following hip fractures and this might help in improving outcomes in our elderly patient population.

\section{Acknowledgements}

Mr J Raubenheimer, Lecturer, Department of Biostatistics at the Faculty of Health, University of the Free State, for statistical analysis of the data.

\section{Ethics statement}

Approval to conduct this research was obtained from the Ethics Committee of the Faculty of Health Sciences, University of the Free State (ECUFS 61/2015), Universitas Academic Hospital Annex and the Provincial Department of Health.

\section{References}

1. Jameson S, Khan S, Baker P, James P, Gray A, Reed M et al. A national analysis of complications following hemiarthroplasty for hip fracture in older patients. QJM. 2012;105(5):455-60.

2. Mundi S, Pindiprolu B, Simunovic N, Bhandari M. Similar mortality rates in hip fracture patients over the past 31 years. Acta Orthopaedica. 2014;85(1):54-59.

3. Sikand M, Wenn R, Moran C. Mortality following surgery for undisplaced intracapsular hip fractures. Injury. 2004;35(10):1015-19.

4. Haleem S, Lutchman L, Mayahi R, Grice J, Parker M. Mortality following hip fracture: Trends and geographical variations over the last 40 years. Injury. 2008;39(10):1157-63.

5. Gregory J, Kostakopoulou K, Cool W, Ford D. One-year outcome for elderly patients with displaced intracapsular fractures of the femoral neck managed non-operatively. Injury. 2010;41(12):1273-76.

6. Omsland T, Emaus N, Tell G, Magnus J, Ahmed L, Holvik K et al. Mortality following the first hip fracture in Norwegian women and men (1999-2008). A NOREPOS study. Bone. 2014;63:81-86.

7. Koh G, Tai B, Ang L, Heng D, Yuan J, Koh W. All-cause and cause-specific mortality after hip fracture among Chinese women and men. Osteoporosis International. 2012;24(7):1981-89.

8. Grønskag A, Romundstad P, Forsmo S, Langhammer A, Schei B. Excess mortality after hip fracture among elderly women in Norway. Osteoporosis International. 2011;23(6):1807-11.

9. Yoon H, Park C, Jang S, Jang S, Lee Y, Ha Y. Incidence and mortality following hip fracture in Korea. Journal of Korean Medical Science. 2011;26(8):1087.

10. 1eBlanc E. Hip fracture and increased short-term but not long-term mortality in healthy older women. Archives of Internal Medicine. 2011;171(20):1831.

11. Costain D, Whitehouse S, Pratt N, Graves S, Ryan P, Crawford R. Perioperative mortality after hemiarthroplasty related to fixation method. Acta Orthopaedica. 2011;82(3):275-81.

12. 1uiz-lbán $M$, Crespo-Hernández $P$, Fernández-Roldán $S$, Díaz-Heredia J, Martínez-Ureña P, Muriel A et al. Cemented hemiarthroplasty after a femoral neck fracture. Survivorship analysis. Revista Española de Cirugía Ortopédica y Traumatología (English Edition). 2008;52(4):206-12.

13. Khan S, Jameson S, Sims A, A'Court J, Reed M, Rangan A et al. Cemented Thompson's hemiarthroplasty in patients with intracapsular neck of femur fractures: survival analysis of 1,670 procedures. European Journal of Orthopaedic Surgery \& Traumatology. 2014;25(4):655-60.

14. Johnston A, Barnsdale L, Smith R, Duncan K, Hutchison J. Change in long-term mortality associated with fractures of the hip. The Journal of Bone and Joint Surgery British volume. 2010;92-B(7):989-93.

15. Yli-Kyyny $T$, Sund $R$, Heinänen $M$, Venesmaa $P$, Kröger $H$. Cemented or uncemented hemiarthroplasty for the treatment of femoral neck fractures? Acta Orthopaedica. 2014;85(1):49-53.

16. Panula J, Pihlajamäki $H$, Mattila $V$, Jaatinen $P$, Vahlberg $T$, Aarnio $P$ et al. Mortality and cause of death in hip fracture patients aged 65 or older - a population-based study. BMC Musculoskeletal Disorders. 2011;12(1). 